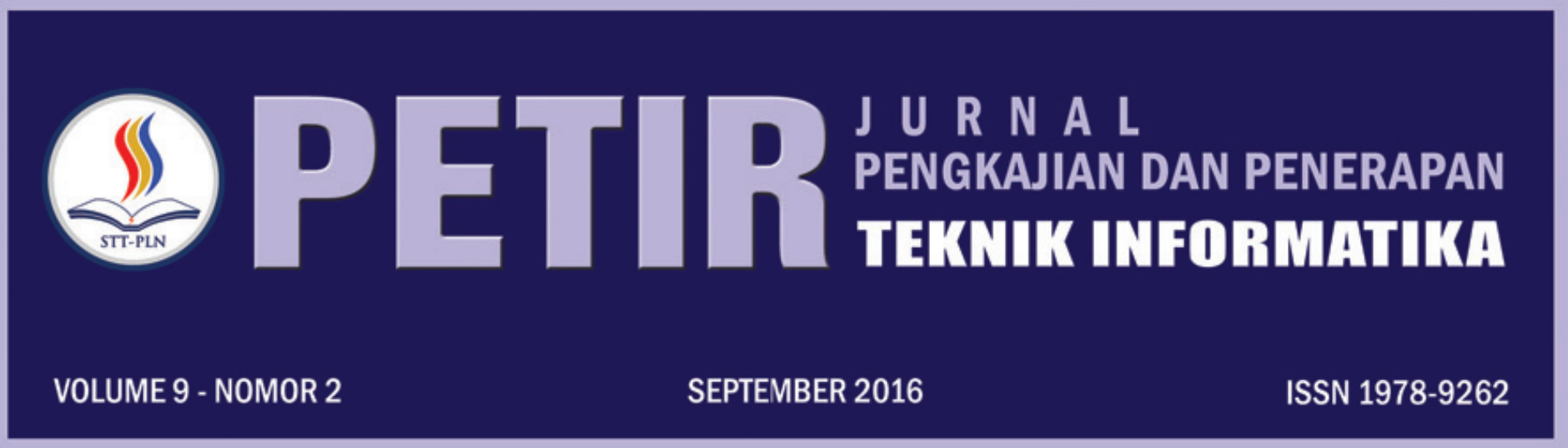

ANALISA SPASIAL UNTUK MELIHAT TINGKAT KESEJAHTERAAN MASYARAKAT DI PROVINSI BANTEN Muhamad Jafar Elly; Reza Pahlevi

PENENTUAN WILAYAH RAWAN PENYAKIT BERBASIS LINGKUNGAN DI JAKARTA TIMUR MENGGUNAKAN SISTEM INFORMASI GEOGRAFIS

Atiqah Meutia Hilda; Muhamad Jafar Elly; Windu Nugroho Cahyo Pamungkas

APLIKASI PENCARIAN USTADZ UNTUK WILAYAH DKI JAKARTA MENGGUNAKAN ALGORITMA HAVERSINE FORMULA BERBASIS ANDROID

Harni Kusniyati; Haries Fadhillah

PERENCANAAN ARSITEKTUR ENTERPRISE PERGURUAN TINGGI DENGAN PENDEKATAAN ENTERPRISE ARCHITECTURE PLANNING (EAP) (STUDI KASUS POLITEKNIK PIKSI GANESHA)

M. Farid Rifai

PERANCANGAN E-KATALOG PADA PERPUSTAKAAN DIGITAL STT-PLN BERBASIS WEB

Yessy Fitriani; Yasni Djamain; Risalatulina Dwi Kurniati

APLIKASI SISTEM GPS KEGIATAN OPERASIONAL PERSAMPAHAN DINAS PENGELOLAAN SAMPAH, PERTAMANAN DAN PEMAKAMAN (DP4) KOTA SUKABUMI

Yasmi Afrizal; Julian Chandra W
PERANCANGAN APLIKASI PENGOLAHAN DATA KAS BERBASIS ONLINE
(STUDI KASUS : KEMENTRIAN ' $X$ ')
Dian Hartanti; Lingga Desyanita

PERANCANGAN SISTEM INFORMASI PESERTA SERTIFIKASI

(Studi kasus LSP Piksi Ganesha)

Hendra Jatnika

RANCANG BANGUN APLIKASI SEC-WAY GUNA PENGINGAT BEPERGIAN DILENGKAPI INFO CUACA DAN CCTV JALAN RAYA LOKASI PILIHAN BERBASIS ANDROID STUDI KASUS DKI JAKARTA

Yasni Djamain; Intan Ratna Sari Yanti; Hari Wibowo

PREDIKSI PENERIMAAN SISWA BARU PADA MADRASAH ALIYAH AS-SAYAFI'IYAH 02 MENGGUNAKAN METODE TIME SERIES

Sarwo; Hermawan

PERANCANGAN SIMULASI MEDIA PEMBELAJARAN DENGAN METODE DIVISION REMAINDER UNTUK PENCARIAN ALAMAT RELATIF PADA PROSES PENEMPATAN DATA

Dewi Arianti Wulandari; Darma Rusjdi

ANALISIS SISTEM PENENTUAN LOKASI GANGGUAN JARINGAN DISTRIBUSI LISTRIK TERINTEGRASI GOOGLE MAP Abdul Haris; Herman Bedi Agtriadi

\begin{tabular}{|c|c|c|c|c|c|c|}
\hline \multirow{2}{*}{ 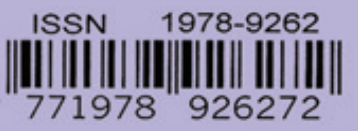 } & \multicolumn{6}{|c|}{ SEKOLAH TINGGI TEKNIK - PLN (STT-PLN) } \\
\hline & PETIR & VOL. 9 & NO. 2 & HAL. 89 - 166 & JAKARTA, SEPTEMBER 2016 & ISSN 1978-9262 \\
\hline
\end{tabular}




\title{
PERANCANGAN E-KATALOG PADA PERPUSTAKAAN DIGITAL STT-PLN BERBASIS WEB
}

\author{
Yessy Fitriani1), Yasni Djamain2), Risalatulina Dwi Kurniati3) \\ Jurusan Teknik Informatika, Sekolah Tinggi Teknik PLN \\ 1Email : yessy.fitriani@sttpln.ac.id \\ Jurusan Teknik Informatika, Sekolah Tinggi Teknik PLN \\ 2Email : yasnidj@yahoo.com \\ Jurusan Teknik Informatika, Sekolah Tinggi Teknik PLN \\ ${ }^{3}$ Email : silverbullet.rd@gmail.com
}

\begin{abstract}
STT-PLN library has had a website before, but there is no catalog features whose books have not owned by the library STT-PLN. This research will discuss about how to design the development of perpusatakaan digital STT-PLN in the added features of e-catalogs.

The application of research methods using User Centered Design (UCD). In this application development using UML (Unified Modeling Language) diagram for designing the research development of perpusatakaan digital STT-PLN which includes use case diagrams, class diagrams, activity diagrams, and sequence diagrams. Solving the problem of system design include database design, application menu hierarchy and application interface design. UML which has been designed and then translated into web-based programming language that is PHP and using MySQL as the database. Then the last application tested using the User Acceptance Test (UAT), the direct testing of applications by users of the application.

Implementation of the development of perpusatakaan digital is obtained results of a dynamic web based applications that can help users in accessing library applications online through the Internet and to members can facilitate the conduct of order books online, as well as facilitate the administrator library to manage the application.
\end{abstract}

Keyword : website, UCD method, e-katalog, UAT method, perpusatakaan digital development

\section{Abstrak}

Perpustakaan STT-PLN telah memiliki website sebelumnya tetapi belum ada fitur katalog yang bukubukunya belum dimiliki oleh perpustakaan STT-PLN. Penelitian ini akan membahas tentang bagaimana merancang pengembangan perpusatakaan digital STT-PLN yang ditambah dengan fitur e-katalog.

Metode penelitian aplikasi ini menggunakan metode User Centered Design (UCD). Dalam pengembangan aplikasi ini menggunakan UML (Unified Modelling Language) diagram untuk merancang penelitian pengembangan aplikasi perpusatakaan digital STT-PLN yang meliputi use case diagram, class diagram, activity diagram, dan sequence diagram. Pemecahan masalah perancangan sistem meliputi perancangan basis data, hierarki menu aplikasi dan perancangan antarmuka aplikasi. Dari UML yang telah dirancang kemudian diterjemahkan ke dalam bahasa pemrograman berbasis web yaitu php dan menggunakan MySQL sebagai basis data. Kemudian terakhir aplikasi diuji coba menggunakan User Acceptance Test (UAT), yaitu pengujian langsung aplikasi dengan pengguna aplikasi.

Implementasi dari pengembangan aplikasi perpusatakaan digital ini didapatkan hasil sebuah aplikasi berbasis web dinamis yang dapat membantu pengguna pada saat mengakses aplikasi perpustakaan secara online melalui jaringan internet dan untuk anggota dapat memudahkan dalam melakukan order buku secara online, serta memudahkan administrator perpustakaan dalam mengelola aplikasi tersebut.

Kata kunci : website, metode UCD (User Centered Design), e-katalog, metode UAT (User Acceptance Test), pengembangan perpusatakaan digital

\section{PENDAHULUAN}

Perpustakaan merupakan suatu tempat yang di dalamnya terdapat berbagai macam koleksi buku. Disetiap institusi pasti memiliki perpustakaan yang menyediakan buku-buku referensi untuk setiap bidang institusi terkait. Perpustakaan ini sangat penting adanya khususnya pada institusi pendidikan. Pada institusi pendidikan, perpustakaan merupakan sumber ilmu dan tempat dimana seseorang dapat menemukan referensi terkait pendidikannya. Dengan semakin berkembangnya sistem informasi, maka perpustakaan pun juga semakin dikembangkan menjadi perpustakaan digital.

Perpustakaan STT-PLN saat ini sudah memiliki dua sistem peminjaman yaitu dengan OPAC (Online Public Access Catalog) dan website online digital library yang memiliki url www.library.sttpln.ac.id. Anggota perpustakaan STT-PLN terdiri dari mahasiswa, dosen dan karyawan STT-PLN. Sistem yang telah berjalan sekarang ini masih perlu banyak perbaikan karena masih banyaknya error sistem pada aplikasi. Untuk website perpustakaan telah memiliki fitur yang lengkap mulai dari peminjaman buku sampai 
dengan riwayat peminjaman buku semua telah ada pada aplikasi website perpustakaan STT-PLN sekarang. Kendalanya adalah jika anggota ingin menggunakan itu semua, mereka wajib melakukan login aplikasi. Sementara itu, mereka tidak memiliki password yang dapat digunakan untuk melakukan login aplikasi. Untuk mendapatkan password tersebut, anggota perpustakaan terdaftar harus meminta kepada petugas perpustakaan. Sebelum itu semua, admin perpustakaan harus menginputkan password yang akan digunakan anggota untuk login.

Permasalahan lain yang dihadapi perpustakaan terkait dengan sistem manajemennya yaitu manajemen katalog buku baru. Setiap tahunnya perpustakaan STT-PLN menambah koleksi buku-buku yang dimiliki oleh perpustakaan dengan cara menyebarkan katalog pemesanan buku ke setiap jurusan untuk diisi oleh dosen-dosen setiap jurusan. Dosen-dosen setiap jurusan mengisi daftar katalog yang dibagikan oleh perpustakaan dengan cara memberi lingkaran pada daftar yang tersedia. Perpustakaan memberikan waktu selama dua minggu untuk jurusan mengisi daftar katalog yang telah disebarkan oleh pihak perpustakaan. Setelah daftar katalog yang telah diisi dikembalikan jurusan ke perpustakaan, pihak perpustakaan mendata kembali buku-buku apa saja yang dibutuhkan jurusan. Permasalahan manajemen katalog buku baru tersebut membutuhkan waktu cukup lama dalam prosesnya. Selain itu, dengan menyebarkan katalog buku baru secara manual, membuat banyak kertas terbuang.

Untuk itulah website perpustakaan kampus STT-PLN ini akan disempurnakan dengan ditambahkan fitur katalog buku dimana nantinya tidak hanya dosen yang dapat memesan tetapi anggota juga akan bisa memesan buku yang dibutuhkan.

\section{LANDASAN TEORI}

Perpustakaan adalah suatu tempat yang didalamnya terdapat koleksi buku-buku. Perpustakaan biasanya menyediakan buku-buku yang tidak banyak dijual di pasaran atau menyediakan buku-buku lama yang masih dapat menjadi referensi untuk orang-orang. Berikut ini pengertian perpustakaan menurut para ahli :

Menurut Sutarno (2006), Perpustakaan adalah mencakup suatu ruangan, bagian dari gedung / bangunan atau gedung tersendiri yang berisi buku-buku koleksi, yang diatur dan disusun demikian rupa, sehingga mudah untuk dicari dan dipergunakan apabila sewaktu-waktu diperlukan oleh pembaca.

Menurut Lasa (2007), Perpustakaan adalah kumpulan atau bangunan fisik sebagai tempat buku dikumpulkan dan disusun menurut sistem tertentu atau keperluan pemakai.

Secara lebih konkrit perpustakaan dapat dirumuskan sebagai suatu unit kerja dari sebuah lembaga pendidikan yang berupa tempat penyimpanan koleksi buku-buku pustaka untuk menunjang proses pendidikan. Dari beberapa pengertian diatas, dapat disimpulkan bahwa perpustakaan adalah tempat untuk mengembangkan informasi dan pengetahuan yang dikelola oleh suatu lembaga pendidikan, sekaligus sebagai sarana edukatif untuk membantu memperlancar cakrawala pendidik dan peserta didik dalam kegiatan belajar mengajar

Sejalan dengan perkembangan zaman, pengertian perpustakaan berubah secara berangsur-angsur. Pada mulanya setiap ada kumpulan buku-buku koleksi yang dikelola secara rapi dan teratur disebut perpustakaan, tetapi karena adanya perkembangan teknologi modern dalam usaha pelestarian dan pengembangan informasi, maka koleksi perpustakaan tidak hanya terbatas buku-buku saja tetapi juga beraneka ragam jenisnya.

Menurut Sutarno NS (2006), Tujuan Perpustakaan adalah untuk menyediakan fasilitas dan sumber informasi dan menjadi pusat pembelajaran. Sedangkan menurut Lasa (2007):

a) Menumbuhkembangkan minat baca dan tulis. Para siswa dan guru dapat memanfaatkan waktu untuk mendapat informasi di perpustakaan. Kebisaan ini mampu menumbuhkan minat baca mereka yang pada akhirnya dapat menimbulkan minat tulis.

b) Mengenalkan teknologi informasi. Perkembangan teknologi informasi harus terus diikuti pelajar dan pengajar. Untuk itu perlu proses pengenalan dan penerapan teknologi informasi dari perpustakaan.

c) Membiasakan akses informasi secara mandiri. Pelajar perlu didorong dan diarahkan untuk memiliki rasa percaya diri dan mandiri untuk mengakses informasi. Hanya orang yang percaya diri dan mandirilah yang mampu mencapai kemajuan.

d) Memupuk bakat dan minat. Bacaan, tayangan gambar, dan musik di perpustakaan mampu menumbuhkan bakat dan minat seseorang. Fakta dan sejarah membuktikan bahwa keberhasilan seseorang itu tidak ditentukan oleh NEM yang tinggi melainkan melalui pengembangan bakat dan minat.

Katalog berasal dari bahasa Latin, Catalogus yang berarti daftar barang atau benda yang disusun untuk tujuan tertentu. Sedangkan e-katalog adalah suatu sistem elektronik yang memuat daftar, jenis, spesifikasi teknis dan harga barang atau jasa tertentu. Contoh katalog dalam pengertian umum adalah Sophie Martin Le Catalogue, katalog penerbit, katalog produk dan lain-lain. Beberapa definisi katalog menurut ilmu perpustakaan dapat disebutkan sebagai berikut :

a. Katalog adalah carik kartu, daftar atau buku yang memuat nama benda atau informasi tertentu yang ingin di beritahukan yang disusun secara berurutan, teratur dan alfabetis, daftar barang-barang yang dilengkapi dengan nama, harga, mutu dan cara pemesanannya, kartu yang membantu pencarian buku-buku di perpustakaan (Kamus Besar Bahasa Indonesia, 2002). 
b. Katalog berarti daftar berbagai jenis koleksi perpustakaan yang disusun menurut sistem tertentu (Fathmi, 2004).

c. Katalog perpustakaan merupakan suatu rekaman atau daftar bahan pustaka yang dimiliki oleh suatu perpustakaan atau beberapa perpustakaan yang disusun menurut aturan dan sistem tertentu (DasarDasar IImu Perpustakaan, 2003).

Dari definisi di atas dapat disimpulkan bahwa katalog merupakan daftar dari koleksi perpustakaan atau beberapa perpustakaan yang disusun secara sistematis, sehingga memungkinkan pengguna perpustakaan dapat mengetahui dengan mudah koleksi apa yang dimiliki oleh perpustakaan dan dimana koleksi tersebut dapat ditemukan.

Menurut Sulistyo-Basuki (1991) tujuan dari Katalog adalah sebagai berikut:

a) Memungkinkan seorang menemukan sebuah buku yang diketahui pengarangnya, judulnya atau subjeknya.

b) Menunjukan buku yang dimiliki perpustakann oleh pengarang tertentu, berdasarkan subjek tertentu dan dalam jenis literatur tertentu.

c) Membantu dalam pemilihan buku berdasarkan edisinya dan berdasarkan karakternya (sastra ataukah berdasarkan topik).

Menurut Qalyubi dkk (2007) menyebutkan

fungsi katalog adalah sebagai berikut :

a. Mencatat karya seseorang pada tajuk yang sama.

b. Menyusun entri pengarang secara tepat sehingga semua karya seseorang berada pada tajuk yang sama.

c. Mencatat semua judul bahan pustaka yang dimiliki suatu perpustakaan.

d. Menunjukkan rujukan silang (cross reference) dari beberapa istilah atau nama-nama yang sama yang digunakan sebagai tajuk. e. Memberikan petunjuk letak atau lokasi bahan pustaka yang disusun pada perpustakaan. Memberikan uraian tentang setiap karya yang dimiliki suatu perpustakaan sehingga pengguna perpustakaan (user) dapat memperoleh informasi yang lengkap tentang karya itu.

\section{METODOLOGI PENELITIAN}

Metode penelitian menggunakan metode UCD dikarenakan pengembangan aplikasi perpusatakaan digital STT-PLN dengan penambahan fitur e-katalog ini harus didasarkan pada pengguna saat pengerjaannya. Aplikasi website perpusatakaan digital yang sekarang berjalan telah digunakan oleh pengguna sehingga dalam pengembangannya dibutuhkan saran dan arahan dari pengguna mengenai kekurangan ataupun error aplikasi yang muncul saat digunakan. Metode UCD yang digunakan merupakan metode yang berfokus pada pengguna oleh karena itu untuk menguji pengembangan perpusatakaan digital ini dibutuhkan UAT (User Acceptance Test) untuk pengujian aplikasinya. UAT (User Acceptance Test) merupakan sebuah pengujian aplikasi yang didasarkan pada analisa kebutuhan pengguna. Untuk merancang penambahan fitur ekatalog pada perpusatkaan digital ST-TPLN, dapat diterjemahkan langkah demi langkah yang ada dalam proses UCD dengan penggambaran mind mapping seperti dibawah ini:

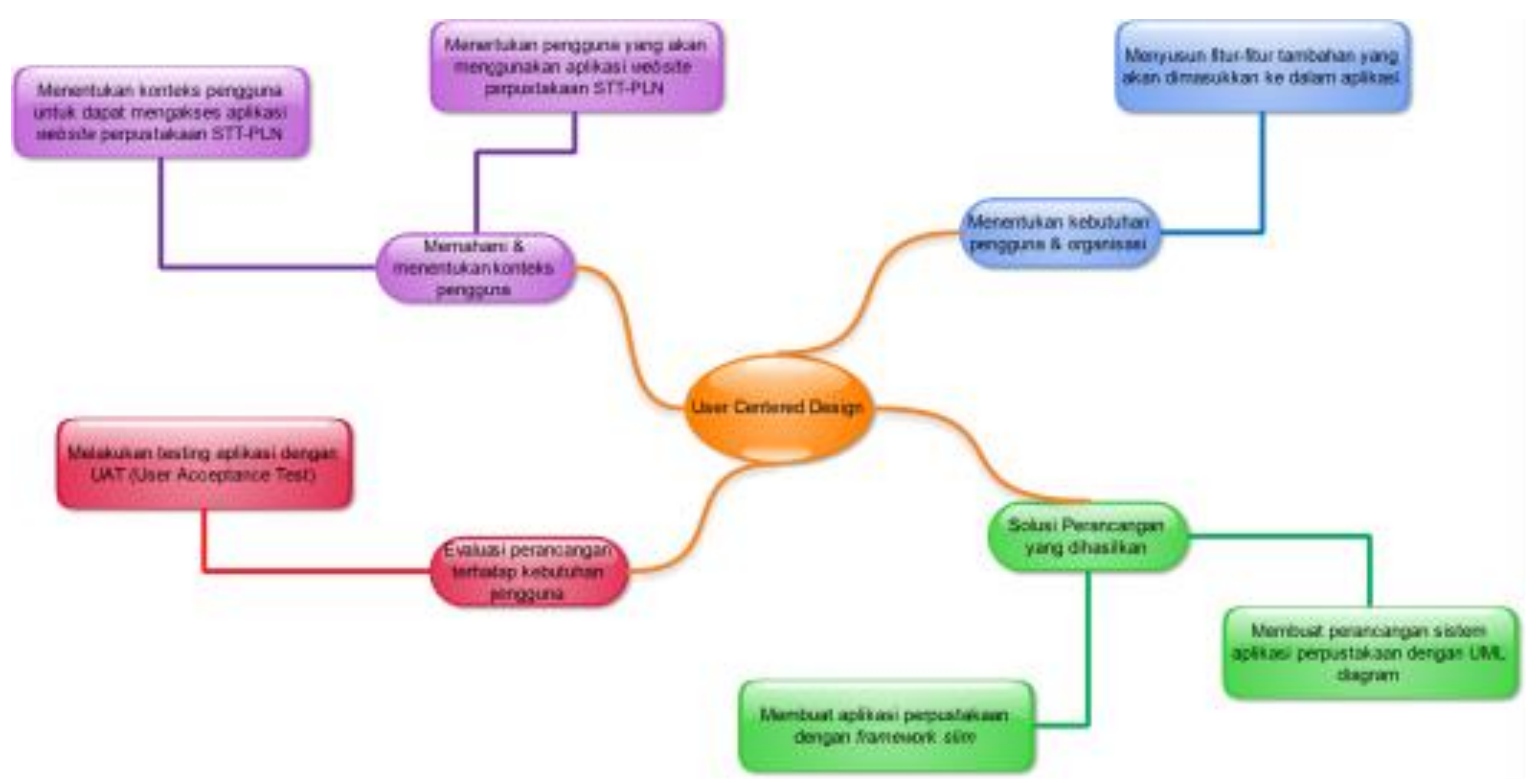

Gambar 1. Mind mapping metode UCD 
Penjelasan mind mapping metode UCD :

A. Memahami dan Menentukan Konteks Pengguna

Pengguna aplikasi perpusatakaan digital perpustakaan STT-PLN ini adalah civitas akademika kampus STT-PLN yang telah terdaftar sebagai anggota perpustakaan. Civitas akademika STT-PLN terdiri dari mahasiswa, dosen dan karyawan kampus STT-PLN. Administrator dari aplikasi perpusatakaan digital ini adalah petugas perpustakaan STT-PLN. Semua pengguna baik itu administrator maupun civitas akademika STT-PLN dapat mengakses perpusatakaan digital perpustakaan STT-PLN melalui url www.library.sttpln.ac.id pada web browser.

B. Menentukan Kebutuhan Pengguna dan Organisasi

Kebutuhan pengguna diperoleh dari hasil diskusi antara penulis dengan pihak perpustakaan STT-PLN yang membahas tentang sistem yang sedang berjalan di perpustakaan sekarang.

C. Solusi Perancangan yang Dihasilkan

Untuk membangun pengembangan perpusatakaan digital perpustakaan STT-PLN dibutuhkan perancangan sistem agar sesuai dengan dibutuhkan pengguna dan pengaplikasiannya tidak keluar dari batasan penelitian. Pada pengembangan perpusatakaan digital $\neg$ perpustakaan STTPLN dengan fitur e-katalog ini menggunakan UML (Unified Modelling Language) diagram untuk membuat perancangan sistem aplikasinya.

D. Evaluasi Perancangan Terhadap Kebutuhan Pengguna

Tahap evaluasi merupakan tahapan terakhir dalam pembuatan suatu aplikasi. Pada tahapan ini aplikasi yang telah dikembangkan akan di uji coba menggunakan UAT (User Acceptance Test) sebagai tester untuk menguji coba aplikasi ini berdasarkan metode User Centered Design (UCD).

\section{HASIL DAN ANALISA}

Sistem yang diusulkan adalah setiap anggota yang telah terdaftar sebagai anggota perpustakaan akan diberikan password random yang dapat digunakan untuk login ke dalam aplikasi, sementara untuk ID anggota tersebut menggunakan nim, nomor identitas dosen dan nomor identitas karyawan kampus STT-PLN. Pengguna aplikasi website perpustakaan ini dikhususkan untuk seluruh civitas akademika STT-PLN yaitu mahasiswa, dosen, dan karyawan STT-PLN. Untuk pihak luar yang bukan merupakan civitas akademika STT-PLN hanya akan diberi akses untuk mencari buku dan melihat buku koleksi perpustakaan STT-PLN. Pada aplikasi ini anggota akan diberikan fitur tambahan yaitu fitur pemesanan buku bahan kuliah. Buku yang dimaksud merupakan buku yang tidak terdapat pada koleksi buku perpustakaan kampus STT-PLN. Selain itu, pada admin ditambahkan fitur menambahkan katalog buku yang dapat dipesan oleh anggota. Katalog tersebut akan ditampilkan pada halaman website dengan status dapat dipesan.

Berikut gambaran alur untuk sistem usulan :

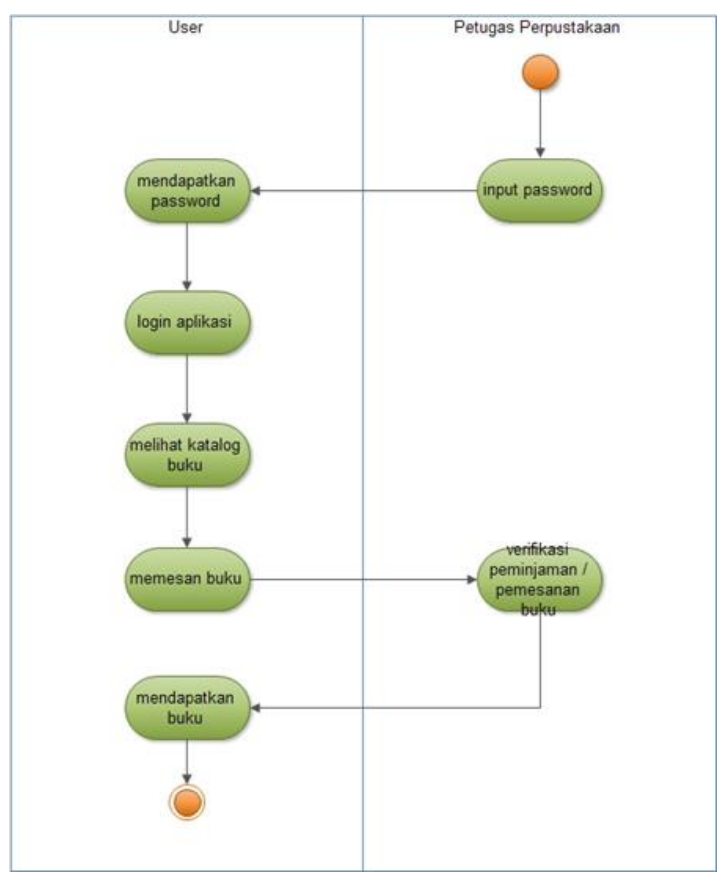

Gambar 2. Alur Sistem Usulan

Gambar diatas merupakan gambaran alur sistem usulan yang akan dikembangkan oleh penulis di dalam penelitian ini. Sistem usulan ini nantinya akan ditambahkan ke dalam website perpustakaan STT-PLN yang telah ada sebagai fitur terbaru.

Perancangan penelitian dimulai dengan merangcang UML (Unified Modelling Language). Tahap pertama yaitu merancang use case diagram. Use Case Diagram digunakan untuk melihat perbedaan hak akses untuk user yang terdiri dari mahasiswa, karyawan dan dosen dengan petugas perpustakaan sebagai administrator sistem perpustakaan. Berikut gambaran use case diagram dari sistem yang akan dikembangkan :

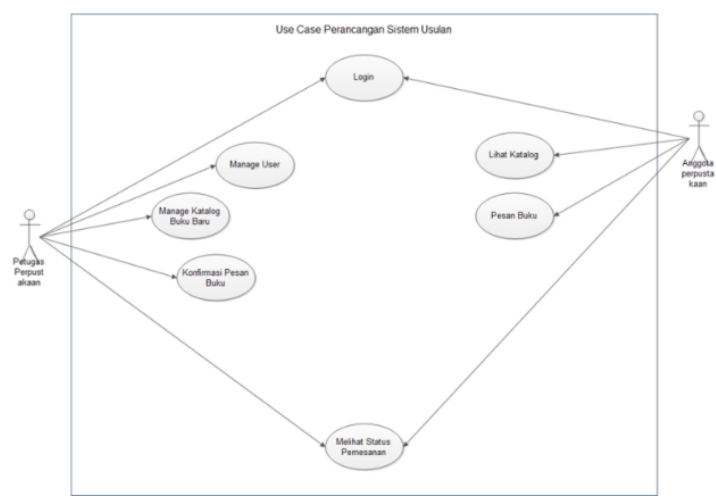

Gambar 3. Use Case Diagram 
Berdasarkan perancangan penelitian yang telah dilakukan,berikut ini hasil screenshot aplikasi pengembangan perpusatakaan digital STT-PLN dengan penambahan fitur e-katalog.

\section{Halaman Beranda Utama}

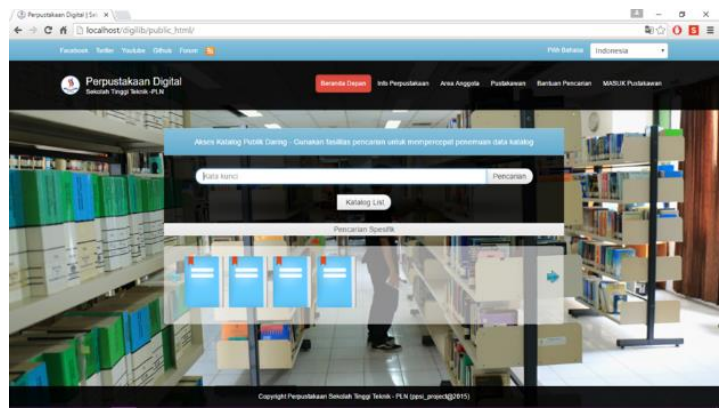

Gambar 4. Halaman Beranda Utama

Gambar 2. merupakan halaman muka saat aplikasi dibuka atau dijalankan. Halaman muka digunakan pengguna untuk mencari buku-buku koleksi perpustakaan dan melihat daftar katalog.

\section{Halaman Login Anggota}

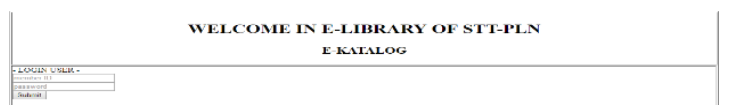

Gambar 5. Halaman Login Anggota

Gambar diatas merupakan halaman area anggota sebelum melakukan login. Sebelum anggota login pada area anggota hanya akan menampilkan form login yang terdiri dari ID anggota dan kata sandi. Anggota perpustakaan yang telah terdaftar dapat melakukan login dengan meminta kata sandi untuk login kepada pihak perpustakaan. Setelah anggota melakukan login, maka akan tampil data anggota seperti gambar dibawah ini :

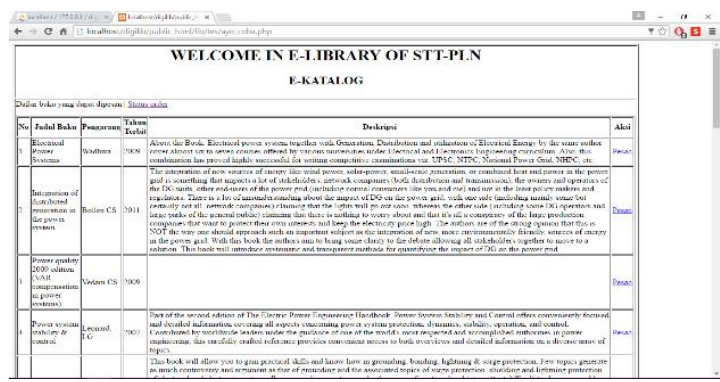

Gambar 6. Halaman Katalog Pemesanan Buku

Pada halaman katalog pemesanan buku tersebut berisi daftar katalog buku yang dapat dipesan oleh anggota. Pada bagian bawah halaman daftar katalog tersebut terdapat form yang dapat diisi oleh anggota apabila buku yang diinginkan oleh anggota tidak terdapat pada daftar yang telah disediakan. Berikut dibawah ini hasil screenshot aplikasi :

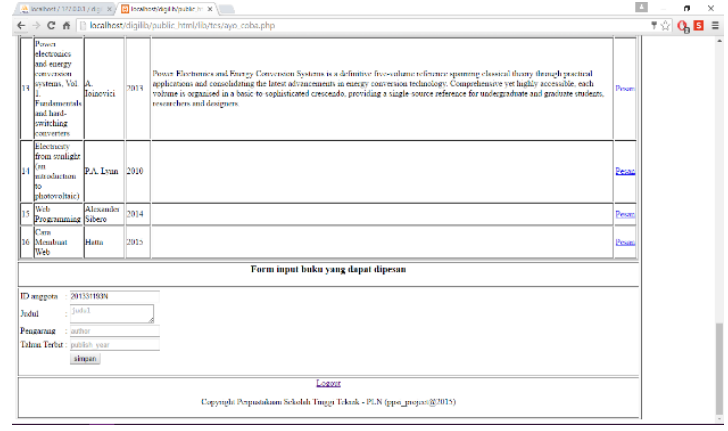

Gambar 7. Form input buku yang dipesan

Dibagian atas halaman katalog pemesanan buku ini terdapat link status order yang apabila diklik akan masuk ke halaman daftar pemesanan buku yang telah dilakukan oleh anggota. Berikut ini gambar halaman status order yang dilakukan oleh anggota :

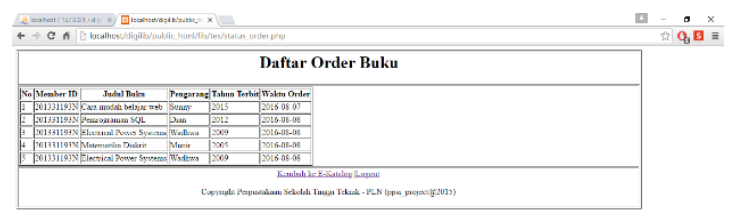

Gambar 8. Halaman Status Order

3. Halaman Daftar Katalog Buku

Halaman daftar katalog yang disediakan oleh perpustakaan yang dapat dipesan oleh anggota. Untuk dapat melakukan pemesanan buku, anggota harus melakukan login ke dalam aplikasi.

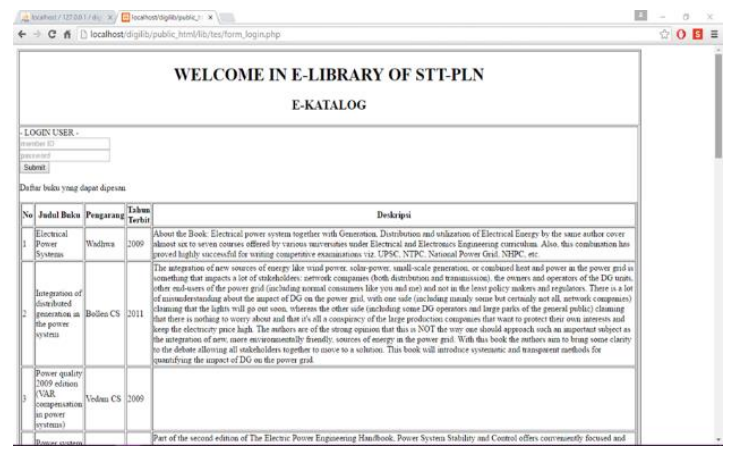

Gambar 9. Halaman Daftar Katalog Buku

\section{Halaman Login Admin}

Halaman masuk admin untuk dapat melakukan pengelolaan aplikasi dan perpustakaan. Agar admin dapat melakukan login, admin membutuhkan username \& password yang telah dibuat sebelumnya dan terdaftar di dalam basis data perpustakaan. 


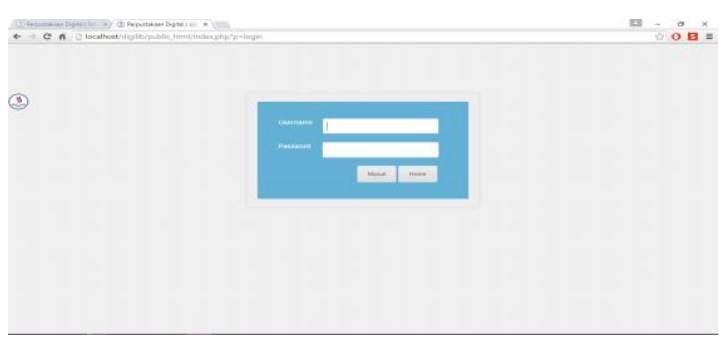

Gambar 10. Halaman Login Admin

5. Halaman Form Input Katalog Buku

Halaman form input katalog buku yang dilakukan oleh admin perpustakaan. Nantinya data buku yang diinputkan didalam form diatas akan ditampilkan di dalam daftar katalog buku.

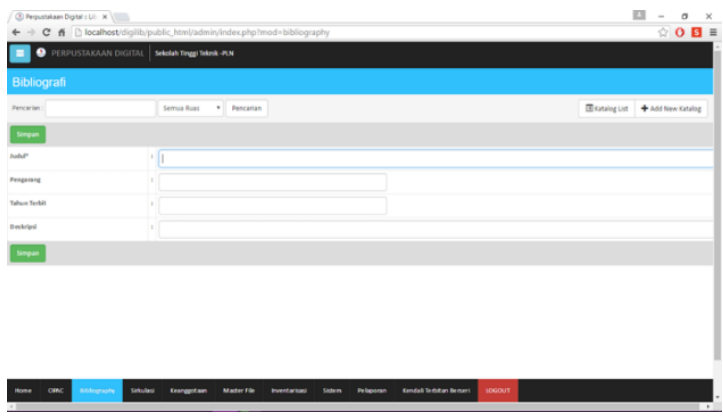

Gambar 11. Halaman Form Input Katalog Buku

\section{Halaman Daftar Order Buku}

Halaman daftar order buku yang dilakukan oleh anggota. Halaman ini hanya dapat dilihat oleh admin perpustakaan. Halaman ini pula yang digunakan oleh admin untuk melakukan konfirmasi pemesanan buku.

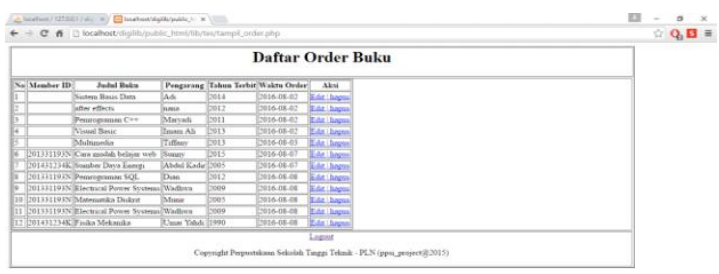

Gambar 12. Halaman Daftar Order Buku

Pengumpulan data dilakukan dengan cara diskusi langsung dengan pihak perpustakaan. Hasil dari data yang telah dikumpulkan dari diskusi tersebut menghasilkan user requirement atau daftar kebutuhan pengguna. Hasil tersebut berupa daftar fitur yang diinginkan oleh pihak perpustakaan. Aplikasi pengembangan perpustakaan digital STTPLN dengan penambahan fitur e-katalog ini melengkapi aplikasi perpusatakaan digital STT-PLN yang telah ada sebelumnya. Aplikasi ini dikembangkan dengan ditambah fitur e-katalog untuk anggota. Anggota dapat melakukan order buku yang diinginkan sesuai daftar yang tertera atau menginput sendiri data buku yang diinginkan oleh anggota. Hal ini akan lebih memudahkan pihak perpustakaan yang selama ini menyebar formulir order buku kepada anggota khususnya dosen.

Dikarenakan pengembangan aplikasi ini disesuaikan dengan kebutuhan dan keinginan pengguna, maka penulis menerapkan metode User Centered Design (UCD). Metode tersebut mengacu kepada pengguna aplikasi pada saat perancangan penelitiannya. Sedangkan untuk pengujian aplikasinya penulis menggunakan User Acceptance Test (UAT). Kelebihan aplikasi ini dari aplikasi sebelumnya adalah anggota dapat melihat data keanggotaannya dan penambahan fitur katalog untuk dosen. Anggota dapat melihat data keanggotaannya dengan melakukan login yang ID anggota dan kata sandi didapat dari perpustakaan. Sedangkan anggota dapat melakukan order buku yang dibutuhkan melalui aplikasi perpusatakaan digital ini.

Pengujian UAT dilakukan kepada 50 orang responden yang terdiri dari admin perpustakaan, anggota perpustakaan yaitu mahasiswa, dosen dan karyawan STT-PLN. Berdasarkan tabel pengujian UAT yang telah dilakukan terlihat bahwa fitur-fitur yang dikembangkan oleh penulis dapat berjalan dengan baik, sesuai hasil kuesioner yang telah diisi oleh responden. Karena pada prinsipnya pengujian UAT (User Acceptance Test) merupakan pengujian yang didasarkan pada kebutuhan pengguna, sehingga pengujian UAT ini sangat cocok dengan metode UCD (User Centered Design). Walaupun semua fitur yang dikembangkan oleh penulis dapat berjalan dengan baik tetapi pada saat dilakukan uji coba dengan pengguna masih terdapat beberapa catatan. Seperti pada fitur detail dosen pembimbing yang tampil pada skripsi, dari sisi admin nama pembimbing skripsi yang diinputkan dapat tampil, tetapi pada sisi anggota perpustakaan tidak dapat tampil. Hal ini dikarenakan terdapat kesalahan pemanggilan field pembimbing dari database. Selain itu, menurut responden tampilan dari fitur yang dikembangkan masih kurang menarik. Dan untuk sisi admin memberi saran agar nantinya dapat melakukan input daftar katalog buku baru dengan excel, karena data buku perpustakaan STT-PLN cukup banyak.

Hasil kuesioner berdasarkan mahasiswa menyarankan bahwa tampilan pada e-katalog untuk diperbaiki, sehingga lebih menarik perhatian pengguna. Tampilan merupakan poin penting dalam hal ketertarikan pengguna terhadap suatu website sehingga semakin menarik tampilan yang kita buat akan semakin banyak pengguna yang menggunakan aplikasi yang kita buat. Hasil kuesioner berdasarkan dosen menyarankan tampilan juga untuk diperbaiki sehingga lebih menarik. Selain itu detail skripsi harap seperti nama dosen pembimbing yang belum muncul juga untuk diperbaiki. Dari dosen dan karyawan meminta agar daftar katalog buku baru harap diperbanyak.

Berdasarkan hasil uji coba dan pengamatan maka dapat dilihat bahwa pengembangan aplikasi perpusatakaan digital dengan penambahan fitur ekatalog dapat membantu anggota untuk melakukan order buku yang diinginkan. Jika tanpa pengembangan aplikasi ini, maka proses order 
buku dari anggota masih akan dilakukan secara manual, yaitu dengan menyebar daftar katalog berbentuk hardprint. Dengan adanya aplikasi ini, user cukup menjalankan aplikasi kemudian melakukan proses - proses secara komputerisasi. Berikut ini tabel perbandingan antara sistem yang berjalan sekarang dengan sistem usulan yang merupakan sistem yang berjalan sebelumnya :

Tabel 1. Tabel Perbandingan Sistem

\begin{tabular}{|c|c|c|c|c|}
\hline No & Fitur & $\begin{array}{l}\text { Sistem } \\
\text { sekarang }\end{array}$ & $\begin{array}{l}\text { Sistem } \\
\text { usulan }\end{array}$ & Keterangan \\
\hline 1. & Login aplikasi & - & Yes & \\
\hline 2. & $\begin{array}{l}\text { Meminjam buku } \\
\text { online }\end{array}$ & Yes & Yes & \\
\hline 3. & $\begin{array}{l}\text { Melihat detail } \\
\text { koleksi buku }\end{array}$ & Yes & Yes & \\
\hline 4. & $\begin{array}{l}\text { Melihat riwayat } \\
\text { peminjaman } \\
\text { buku }\end{array}$ & - & Yes & \\
\hline 5. & $\begin{array}{l}\text { Memesan buku } \\
\text { baru }\end{array}$ & - & Yes & \\
\hline 6. & $\begin{array}{l}\text { Melihat status } \\
\text { pemesanan } \\
\text { buku }\end{array}$ & - & Yes & \\
\hline 7. & $\begin{array}{l}\text { Pada skripsi } \\
\text { terdapat detail } \\
\text { nim dan jurusan }\end{array}$ & - & Yes & \\
\hline 8. & $\begin{array}{l}\text { Pada skripsi } \\
\text { terdapat detail } \\
\text { nama } \\
\text { pembimbing }\end{array}$ & - & Yes & \\
\hline 9. & $\begin{array}{l}\text { Menginput } \\
\text { daftar katalog } \\
\text { buku baru }\end{array}$ & - & Yes & \\
\hline 10. & $\begin{array}{l}\text { Mengkonfirmasi } \\
\text { pemesanan } \\
\text { buku baru }\end{array}$ & - & Yes & \\
\hline 11. & $\begin{array}{l}\text { Menginput } \\
\text { katalog buku } \\
\text { melalui excel }\end{array}$ & - & - & \\
\hline
\end{tabular}

Dari tabel diatas dapat dilihat perbandingan antara sistem yang sedang berjalan dan sistem yang telah dikembangkan. Pada sistem yang telah dikembangkan, fitur katalog pemesanan buku baru dapat berjalan dengan baik dan sesuai dengan keinginan pengguna serta kebutuhan pengguna.

Keuntungan atau kelebihan yang dapat diperoleh jika menggunakan aplikasi ini diantanya adalah petugas perpustakaan tidak lagi menyebar daftar katalog berbentuk hardprint ke anggota. Anggota juga dapat melihat data buku yang ada di katalog lebih detail. Terakhir dengan pengembangan aplikasi ini akan lebih memudahkan petugas perpustakaan dalam melakukan pendataan buku untuk pengadaan koleksi buku perpustakaan terbaru.

Selain kelebihan yang telah dijabarkan sebelumnya terdapat juga kelemahan dari pengembangan sistem yang dibuat yaitu aplikasi ini belum dapat menginput buku dalam jumlah besar, harus satu per satu untuk menginput katalog buku.

\section{KESIMPULAN}

Dari pembahasan yang telah dijabarkan sebelumnya maka dapat disimpulkan sebagai berikut :

Aplikasi pengembangan perpusatakaan digital dengan penambahan fitur e-katalog ini dirancang dengan pendekatan UCD (User Centered Design), pada tahapan desain sistemnya untuk aplikasi ini dirancang dengan UML (Unified Modelling Language) yang terdiri dari use case diagram, class diagram, activity diagram dan sequence diagram. Terakhir aplikasi ini diuji coba dengan UAT (User Acceptance Test). Dengan aplikasi pengembangan perpusatakaan digital dengan fitur e-katalog membantu anggota dalam memesan buku secara online dengan mudah. Fitur-fitur yang terdapat pada pengembangan aplikasi perpusatakaan digital dapat berjalan dengan baik berdasarkan hasil pengujian dengan UAT (User Acceptance Test).

\section{DAFTAR PUSTAKA}

Arief. (2013, Februari 14). Pengertian UML. Juni 10, 2016. http://informatika.web.id/pengertianuml.htm

Kadir, Abdul. (2009). Dasar Perancangan \& Implementasi. Yogyakarta : Penerbit Andi.

Kamus Besar Bahasa Indonesia. July 30, 2016. http://kbbi.web.id/katalog.

Legianto. (2013). Perancangan Katalog Produk Berbasis Web Menggunakan Metode User Centered Design Pada CV Creative Bah Adzka Grafika. Medan : Jurnal Informatika.

Nugroho, Adi. (2014). Sistem Basis Data Oracle 10g. Yogyakarta : Penerbit Andi.

Patula, Anthonio Febrianto, dkk. (2015). Implementasi Metode User Centered Design Dalam Perancangan Aplikasi Pembelajaran VLAN \& Inter-VLAN Routing. Jurnal Informatika.

Pusat Bahasa Departemen Pendidikan Nasional Republik Indonesia. July 31, 2016. http://badanbahasa.kemdikbud.go.id/kbbi/inde x.php

Putri, Sri Yani. (2013). Perancangan Sistem Informasi Sekolah Berbasis Web Dengan Menerapkan Metode User Centered Design (Studi Kasus : SMP Negeri 1 Tanjung Morawa). Medan : Jurnal Informatika.

Rangga, L Alvian. (2012). Penerapan metode User Centered Design Pada Sistem Akademik MAN 2 Mataram Berbasis Mobile Android. Semarang : Jurnal Informatika.

Rosa, A. S., \& Shalahuddin, M. (2014). Rekayasa Perangkat Lunak Terstruktur dan Berorientasi Objek. Bandung : Penerbit Informatika.

Sanggra, dkk. (2010). Acceptance Testing. Juli 31, 2016.

http://www.kompasiana.com/sanggra.ocha.pe pi/acceptancetesting_5500516ea333114a73510787

Sari, Rhomita, dkk. (2015). Rancangan Lowongan Kerja Online Menggunakan Metode User Centered Design (Studi Kasus : Bussiness Placement Center STMIK AMIKOM Yogyakarta). Yogyakarta : Jurnal Informatika.

Sibero, Alexander F.K. (2013). Web Programming Power Pack. Yogyakarta : Penerbit Mediakom. 